\title{
Digital Innovation Hubs supporting SMEs digital transformation
}

\author{
Claudio Sassanelli \\ Department of Economics, \\ Management and Industrial \\ Engineering \\ Politecnico di Milano \\ Milano, Italy \\ claudio.sassanelli@polimi.it
}

\author{
Sergio Terzi \\ Department of Economics, \\ Management and Industrial \\ Engineering \\ Politecnico di Milano \\ Milano, Italy \\ sergio.terzi@polimi.it
}

\author{
Hervé Panetto \\ Université de Lorraine \\ CNRS, CRAN \\ Nancy, France \\ herve.panetto@univ-lorraine.fr
}

\author{
Guy Doumeingts \\ University of Bordeaux \\ INTEROP-Vlab \\ guy.doumeingts@interop-vlab.eu
}

\begin{abstract}
In today's manufacturing domain, companies need to be able to adopt digital technologies, joining the Industry 4.0 paradigm and, more in particular, the Cyber-Physical Systems (CPS) revolution. However, several hurdles have been detected for companies' digital transition. Needing help to become more competitive by improving their business/production processes by means of digital technology, Digital Innovation Hubs (DIHs) have been identified as a strategic means to support companies' digital transformation, especially SMEs, and foster digital technologies' adoption in their business. However, the set of services provided by DIHs and composing their service portfolios still need to be clearly defined and adequately grouped to be then extensively considered in the DIHs. This paper presents a literature review to provide theoretical evidence and to raise the need to extend the traditional Ecosystem-Technology-Business (ETB)-based service portfolio of DIHs with two further dimensions: skills and data. This paves the way to the final consolidation, application and adoption of the forthcoming Data-driven BusinessEcosystem- Skills-Technology (D-BEST) reference model aimed at configuring DIHs' service portfolio and instantiating them from an Industry 4.0 digital perspective.
\end{abstract}

Keywords-Digital Innovation Hub, Service portfolio, Digital Transformation, SME

\section{INTRODUCTION}

In today's manufacturing domain, companies need to be able to adopt digital technologies, joining the Industry 4.0 paradigm and, more in particular, the Cyber-Physical Systems (CPS) revolution. The Industry 4.0 (I4.0), being more a technological paradigm, grounded the technology need paradigm on nine building blocks [1]: big data and analytics, autonomous robots and vehicles, additive manufacturing, simulation, augmented and virtual reality, horizontal/vertical system integration, Internet of Things (IoT), cloud fog and edge technologies, and blockchain and cyber-security. In this context, from a technological point of view, connected systems can interact between each other using standard Internet-based protocols and can analyse data to predict failure, configure themselves, and self-adapt to changes; in other words, being sustainable and resilient.

However, along this transition, often for companies, to demonstrate a suitable digital technology readiness, it could be not enough to deploy new digital technologies in their manufacturing plant. They need to be able to adequately employ these kind of technologies in value-added processes for exploiting their full potentialities, and thus reaching a suitable digital maturity [2].

In 2016, Digital Innovation Hubs (DIHs) have been considered (together with Partnerships \& Platforms, Skills \& Jobs and Regulatory Framework) one of the four key elements of the Digitizing European Industry (DEI) strategy [3]. Providing a proper definition, a DIH is a single organisation or a coordinated group of organisations with complementary expertise, with a not-for-profit objective that support companies - especially SMEs and mid-caps - and/or the public sector in their digital transformation [4].

DIHs provide their stakeholders with several assets that help companies to become more competitive by improving their business/production processes by means of digital technology). They offer four main types of functions:

1. test before invest (to "raise awareness and provide, or ensure access to, digital transformation expertise, know-how and services, including testing and experimentation facilities"),

2. skills and training (to "provide support in the area of advanced digital skills"),

3. support to find investments ("to support companies, especially SMEs and start-ups, organisations and public administrations to become more competitive and improve their business models through use of new technologies covered by the Program"),

4. innovation ecosystem and networking (to "act as facilitator to bring together industry, businesses and administrations which are in need of new technological solutions on one side, with companies, notably start-ups and SMEs that have market-ready solutions on the other side").

To address these four main functions in the digital domain, so far three main dimensions of services (i.e. Ecosystem, Technology and Business (ETB)), to be provided by DIHs to their stakeholders, have been detected [5]. To date, they represent the main dimensions on which DIHs' service 
portfolio should be structured, leading to the definition of the ETB model. The objective of this paper is to both provide theoretical evidence and raise the need of extending the three dimensions of the traditional service portfolio of DIHs, based on the ETB dimensions, with other two, Skills and Data. To do this, a literature review has been conducted.

The paper is structured as follows. Section 2 introduces the research context, clarifying the concepts of service, service portfolio and service catalogue and introducing the mostly used and common model to structure DIH's service portfolio. Section 3 presents the research methodology and Section 4 provides the results of the literature review conducted. Finally, Section 5 is dedicated to discussion of results and Section 6 concludes the paper and paves the way for further research.

\section{RESEARCH CONTEXT}

\section{a. Service portfolio and service catalogue}

Companies need to take into consideration the concept of portfolio management, either separately for products or services or with a combined twofold perspective. The concept of portfolio management was first introduced by [6] with the aim to prove that diversification of an investment portfolio is preferable to a homogenous portfolio based on the dimensions risk and return. The aims of portfolio management can be clustered in three main categories: (i) maximization of value against one or more business objectives, (ii) balancing, in order to manage the overall risk of the portfolio, (iii) strategic alignment of the portfolio with the strategy [7]. Service portfolio management has been recently introduced in the Information Technology (IT) context [8]. Due to the rapid changing of business environments, Banerjee and Aziz (2007) proposed a ServiceOriented Architecture (SOA) of service portfolio to support its integration, reusability, loose coupling, extensibility and interoperability. The key concepts of the SOA proposed are the communications among the service consumer (who consumes services from the Service Provider to deliver a particular business process), service provider (who provides services based on a pre-defined service contract that guarantees a minimum service level which may include performance, reliability, and usage cost), and service registry (that holds the descriptions and contracts associated with the services available for consumption). The communication among these three elements can address the business changes. Figure 1 shows that the Service Consumer requests services to the Service Registry and binds to the services over a transport, while the Service Provider addresses this request and publishes the services and its contract to the Service Registry. The Service Consumer can discover and access the service through the Service Registry [10].

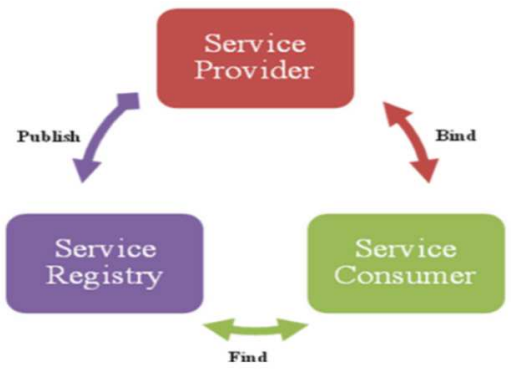

Fig. 1. The communication about service portfolio (adopted by Arsanjani (2004))
Concerning the design of a service portfolio, three levels need to be considered [11]. The conceptual view aids the service conceptualization and the need of governance. The logical view supports the definition of the architecture components for the service conceptualization. The physical view identifies the (programming) implementation of the services. Focusing on the conceptual view, as shown in Figure 2, two main parts need to be considered for analysing a service portfolio: the catalogue and the pipeline. The catalogue services are composed of the active and retired services. The pipeline consists of services under development for a given marketplace, considered in the service design process. Thus, it has to be said that a service portfolio can include services that are not yet developed, but exist only at a conceptual level [12], [13].

In the SOA domain, the terms registry, repository, and catalogue are used as synonyms, representing a technological middleware solution for managing the increasing SOA adoption in organizations. From a managerial point of view [14], they support the decision-making process in regard to managing the service lifecycle in the introduction of new services, the improvement or change of existing services, the retirement of existing services, business decisions on the bundling of multiple services into one package.

Wrapping up, the service catalogue is visible to customers, like a menu of services available to customers. It provides users and customers with the means of understanding what services they can actually use. Different views of the service catalogue can provide service details and information in a format that is understood by the relevant audience. The service catalogue is the only part of the overall service portfolio that can recover costs or earn profits [8].

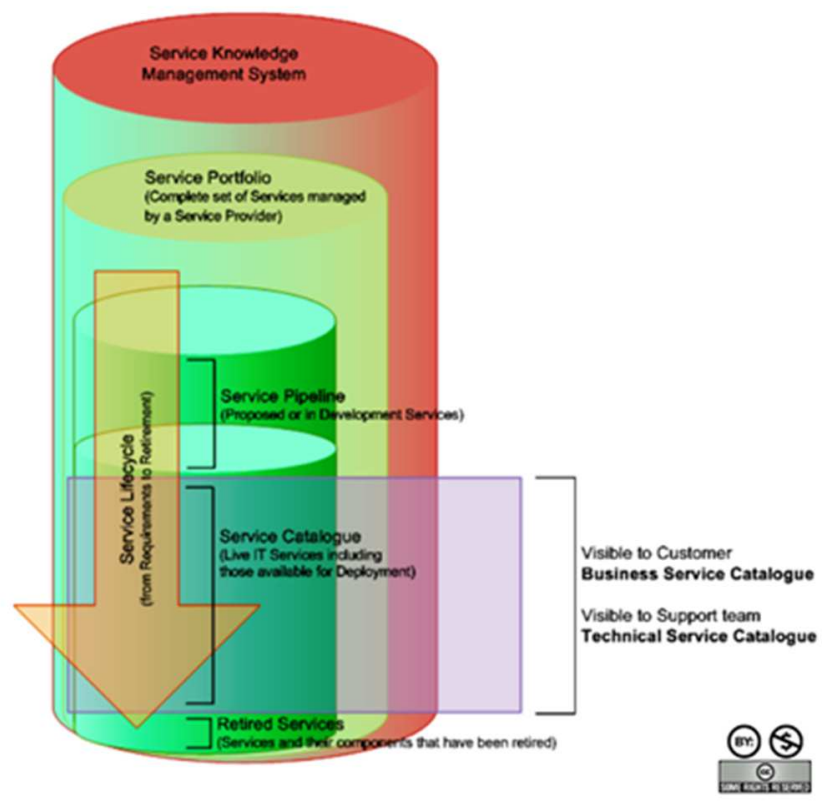

Fig. 2. Service Portfolio, Service Catalogue and Service Pipeline (adopted by (Rudd and Lloyd, 2007)).

b. The Ecosystem-Technology-Business (ETB) model The development of the ETB model occurred over 8 years, starting in 2012. The origin is found in the Multi-Key Enabling Technologies (mKETs) pilot lines project (20122014) [15].

In 2016 the first structure of the ETB model was defined [5]. It was based on assessments of well-developed organizations 
that were a DIH (e.g., the Manufacturing Technology Center, some Dutch field-labs, IMEC (today one of the world-leading R\&D and innovation hub in nanoelectronics and digital technology)), as well as discussions during the Mentoring programme with the 29 emerging DIHs.

In the period 2016-today, the approach was further refined during many workshops, where DIHs, Competence Centres (CCs) and regional authorities were trained to become a DIH. During each workshop and visit to a DIH/CC the approach was evaluated and tweaked. Therefore, the resulting approach is based on the assessment and evaluation of around 75 DIHs/CCs.

Recently, the approach was further assessed in various Innovation Actions (IAs) and Coordination and Support Actions (CSAs), which now are using it as a backbone to assess their DIH-members (SmartEEs, Trinity, SmartAgriHubs [16]).

Finally, the ETB model has also been adopted in the MIDIH ('Manufacturing Industry Digital Innovation Hubs') project [17], conceiving a first draft of its extended version, the ETBSD model [18], by now named (to give evidence to the great importance of Data for DIHs) the Data-driven BusinessEcosystem-Skills-Technology (D-BEST) model, further improved in the DIH4CPS project ${ }^{1}$.

\section{RESEARCH METHOD}

This paper, after defining and enlightening the differences between service portfolio and catalogue, focuses on service portfolio management in the context of DIHs providing theoretical evidence and raising the need to extend the Ecosystem-Technology-Business model of DIHs with Skills and Data dimensions. To do this, a literature review has been conducted. Each of the five dimensions considered has been investigated in the domain of digital technologies and Industry 4.0. Therefore, per each of the five categories of the D-BEST model, a dedicated literature review has been conducted. The words "Industry 4.0" or "digital technology" were paired time by time with "Ecosystem", "Technology", "Business", "Skills" and "Data".

In the following section, the results of the literature review are provided per each dimension to give their specific theoretical background and to improve their understanding. The analyses provided for data and skills dimensions are deeper and more detailed since they refer to the parts that have been considered in this research to directly extend DIH's ETB-based services portfolio.

\section{RESUlTS}

\section{A. Ecosystem}

The word ecosystem was coined in 1935 by a British Ecologist Arthur Tansley [19], initially to represent a community of living organisms which interact with each other but also with its environment, knowing that this environment has an influence on the development of the community and that the various organisms are in competition.

In 1993, James F. Moore adapted the concept described by Tansley to the Business domain and published an article in the Harvard Business Review titled "Predators and Prey: A New
Ecology of Competition", winning the McKinsey Award [20]. In the economic domain, heterogeneous entities like large original equipment manufacturers, SMEs, Technical Centres, Universities, Research Centres, individual professionals, employees, citizens, and consumers cooperate to create a powerful system to compete on the market by continuously adapting and improving their resilience. These concepts have been largely disseminated. For example in the European Project MSEE [21], one of the big challenges was to transform current manufacturing hierarchical supply chains into manufacturing open ecosystems, i.e. to define and implement business processes and policies to support collaborative innovation in a secure industrial environment and a new collaborative architecture for ESA (Enterprise Software and Applications), to support business-IT interaction and distributed decision making.

In ecosystem there is the word "system" that needs to be taken in account. There are several definitions of a system. To follow the concepts of Ecosystem, the system theory [22], [23] is used. In this context, a system is defined as a set of elements having attributes and relations between them, forming a particular structure to reach these objectives, by using several functions and processes. A function is static, for example "the purchasing of materials in order to manufacture the parts". A process is dynamic: "the succession of operations for a given order to manufacture the part". A system has a boundary which delimits the elements belonging to the system and those which are outside in the environment. For example, the market is outside of the manufacturing system but has an influence on its behaviour. If the environment changes, also the system could be affected, evolving according to the time. Thus, it is important particularly in the design phase of the system to take in account the necessity to develop not only robust but also agile systems able to react to any perturbation. Looking at the extant literature, the Theory of Hierarchical, Multilevel Systems [24] allowed to design a structure with a decentralised and coherent decision-making.

In conclusion, a DIH (or a set of DIHs) is a business ecosystem, consisting of a community of interconnected organizations with precise objectives in a specific environment. It is important to give a great attention to the various entities which compose the DIH to maintain the reaching of the assigned objectives.

\section{B. Technology}

The I4.0 has applied, as a new production system, new technologies to manufacturing, influencing all the activities linked to manufacturing, from planning to processes, including also products and work organisation [25]. Gathered under the umbrella of Industry 4.0 [26], these technologies can contribute to address a threefold scope: (i) Digitization and integration of vertical and horizontal value chains, (ii) Digitization of product and service offerings, (iii) Digital business models and customer access. In particular, they have been grouped in 11 different types (among which IoT platforms, 3D printing, smart sensors, augmented reality), leading to a huge number of practical applications for manufacturers.

\footnotetext{
1 DIH4CPS - Digital Innovation Hub for Cyber-Physical. "Fostering DIHs for Embedding

Interoperability in Cyber-Physical Systems of European SMEs" H2020 project n 872548
} 
Among them, a relevant and complex type of technology is represented by the Cyber-Physical System (CPS) and in particular the Cyber-Physical Production System (CPPS) [27]. The industrial production has evolved towards small lots production and customized production [28], also directly involving customers in business and value-added development processes. Companies increasingly recognized the huge heterogeneity of customer demands and attempted to transform them into a business opportunity [29]. However, giving the customer a product tailored to their individual needs and producing at low manufacturing costs is still usually considered a hard task. Mass customization was introduced to link the concept of the low costs of mass production with the flexibility of individual customization [30]. However, a company willing to provide individualized goods following the concept of mass customisation, needs to reflect upon several questions [29]. First, companies must identify the needs of their potential customers, defining the solution space development. Second, reasonable costs need to be assured by a robust and flexible process design. Third, the offer has to be communicated to potential customers, enabling customers to fulfil their co-creation task specifying their needs, i.e., customer choice navigation. To address and support these activities, companies require a "technology stack", a technology-based infrastructure, composed by a series of layers [31]. As a result, four new sets of product functions and capabilities were enabled: monitoring, control, optimization, and autonomy. Each capability can activate the following one and thus gradually drive the surge of digital technologies adoption in manufacturing companies [32]. Intelligent systems are linked to the rest of the world through connectivity components amplifying their capabilities and value. Ports, antennae and protocols enable product connections with the physical web (composed by web technologies plus IoT) [33]. However, to obtain more efficient solutions, autonomous and cooperative components connected to each other are needed, able to put in relation the various level of the structure of management (to decentralise the decision making to be more agile by improving the vertical organisation). By this way it will be possible to develop autonomy, cooperation, optimisation and responsiveness. Among the various techniques to be used, can be mentioned Artificial Intelligence and Machine Learning.

\section{Business}

I4.0 has an impact on traditional business model where new industrial digitalization challenges and features are addressed. As a consequence, this impact influences the creation, delivery, and capture of value through the reconfiguration of Business/Service Models [34]. Among the different approaches affecting Business Models are the service-oriented and the network-oriented. In the serviceoriented approach, companies are expanding their roles to cover a hybrid solution which include not just the product but also the service [35]. In the network-oriented approach the creation on new value is performed through an ecosystem [34].

According to DEI's Working Group 1 [36], DIHs play an important role in helping companies in bringing their ideas to market through the offer of a wide range of services, such as: awareness-raising, brokerage, technical support, concept development and prototyping.

\section{Skills}

The Fourth Industrial Revolution has created a world where physical and virtual manufacturing systems cooperate with each other in a flexible way allowing the production of extremely customized products and the creation of new operating models [37]. The raising of I4.0 enabling technologies [1] is bringing many advantages but some challenges must be considered too. A recent research [38] has raised that one of the main problems is the skills shortage [39]. To maintain the level of competitiveness both new hard skills and soft skills are needed [1], [40]. At this purpose, the relevance of human capital for the economic growth of firms was demonstrated since the '60s [41]-[43] and now is commonly acknowledged as a "competitive weapon". The literature presents several studies investigating the skills shortage problem, together with an initial analysis of new and enhanced skills. In particular, Acerbi, Assiani and Taisch (2019) identified the required hard and soft skills and then associated them to each job profile which today is present in a digitalized manufacturing reality. The skills identified were divided into two main classes (hard skills and soft skills) and then the job profiles were outlined by assigning them the related sets of skills [44]. Several authors focussed on technical skills. For example, Koch et al. (2017) focused on maintenance process using co-bots to support operator activities. On the same stream, focusing on the production environment, Malik and Bilberg (2017) highlighted the need to integrate human activities with automated systems. Instead, Prifti et al. (2017) studied the technical skills changes considering three main domains: Information System (IS), Information Technology (IT), and Engineering. Even if the focus of the majority of these authors reported above is on technical skills, also the soft skills are considered fundamental in this era (e.g. [48]).

However, this change has not a necessarily negative impact on companies. [49] unveiled that the percentage of new job profiles is higher than the percentage of those that will disappear. To prevent job disruption, some solutions have to be implemented: (i) retraining; (ii) increased effort of countries to educate people with new required skills both high technical and soft skills, with particular attention to creativity and innovative problem solving; (iii) hiring of external resources, or finding ways to retain workers (for example by increasing their wages); and (iv) lifelong training to cope with the acceleration of the job market change rate [49]-[52].

Additionally, manufacturing companies, willing to digitalize their industrial processes, need to balance their investments in human capital and technologies, not neglecting that new skills are needed to not pursue the wrong direction. Indeed, as reported by WEF, [54], the necessity of people experts in the usage of both innovative analytical tools and user interface has to be considered. I4.0 applies new technologies to manufacturing, strongly affecting all the activities linked to manufacturing, from planning to processes, involving products and work organisation [25]. For this reason, investing in this kind of technologies could often not be enough to ameliorate competitiveness on the market and to pursue effectively the I4.0 transition. First of all, manufacturing companies need to understand which is their 
digital status quo. [2] developed a methodology aimed at practically investigating the maturity level of manufacturing industries to integrate digital technologies along their valueadding processes, with a special focus on new product development process. They combined four already existing assessment models and analysis methods aimed at evaluating and assessing different but intertwined aspects in the company. Together, not only do they give an overarching assessment of the company adding value processes, but also find the main wastes occurring in them (hurdles for the company's transition towards an industrial digitization). However, if adequately addressed, they represent the way for the company to go towards a more efficient and effective product-centric knowledge management and continuous improvement approach. Indeed, based on them, the method proposed by [2] is able to plan possible interventions to improve the existing situation, first re-modelling the organizational structure (based on people's training and empowerment) to support the changes to be enacted, and then streamlining the order micro-processes' as a key to solve macro-problems and to pave the way to the adoption of informative systems in the organization.

\section{E. Data}

I4.0 is linked to the recent developments in production processes and their automation and represents a very broad domain including production processes, efficiency, data management, relationship with consumers, competitiveness, and much more [55]. Today, I4.0 is a technological paradigm which is embedded within what we call "Industry of the future," which is a larger paradigm including not only technology [56] but also humans and organisations.. These technologies play a strategic role towards the transition and the key development of more intelligent manufacturing processes (including devices, machines, modules, and products). In this context, the processes of information exchange, action and control will be mutually stimulated, being directly connected to an intelligent manufacturing environment [57]. [53] highlighted that the most required roles in the future will be related to data management, data security, software development, programming, data science, and analytics. Information and Communication Technologies (ICT) are spreading and affecting all the aspects of industrial and manufacturing systems, fostering the generation of huge quantities of industrial data [58]. Nevertheless, to fully exploit the benefits of I4.0, companies must cope with seven major categories of challenges (including data management and integration, knowledge-driven, process, security, capital, workforce, and education) [56]. Among these challenges targeted by the I4.0 paradigm, over-connectivity and data management abilities enable the emergence of more flexible and reactive control systems, based on the cooperation of autonomous and connected entities in the decision-making process. After detecting 10 key enablers for I4.0 (sustainability, secure communication/cyber-resilience, realtime capabilities, process virtualization, service orientation, interoperability, adaptability, big data analysis, autonomous and decentralized support systems, connectivity), [59] presented the holonic paradigm as the most important of Intelligent Manufacturing Systems. They claimed that current Holonic Control Architectures (HCAs) can partly fulfil Industry 4.0 key enablers, leaving to extensive discussion some remaining unfulfilled key enablers. Some research directions that could lead to the new HCAs were provided, e.g., Data-oriented HCAs integrating AI functions to prevent/exploit the Big Data to increase reactivity and adaptability. Other suggested areas are Performance-proven Dynamic HCAs, Digital Twin-based HCAs, Cyber-Secure cloud-based HCAs and Sustainable HCAs.

Regarding the last point on sustainability, according to [60], big data-driven sustainable supply chains represent a big chance, based on the fact that the potential benefits of integrating digital technologies and supply chain management have been assessed in literature.

Instead, based on the selection of important data properties (volume, variety, traffic and criticality) applied to networked industrial environments, [58] developed a taxonomy of the latest advances in industrial data enabling technologies and data centric services, going from the field level deep in the physical deployments up to the cloud and applications level, also identifying open challenges for future research. In addition, they provided a detailed outline of recent industrial architectural designs with respect to their data management philosophy (data presence, coordination, and computation) and the extent of their distributiveness.

In addition, connecting in a unique environment processes, systems and people, data- and information-driven transformation is playing a strategic role to drive towards the I4.0 paradigm. In this context, manufacturing companies need to combine diverse sources of knowledge deployed on different technological layers. Considering factors as data interconnection and information transparency, [61] developed a framework enabling access to knowledge from the different data sources available, including those coming from operators. To address interoperability, new (public and encrypted) data management solution to ensure information transparency were needed, enabling data semantics analysis, and giving a consistent context to permit data fusion. On the other hand, industrial internet platforms give the possibility to approach, manage and control data, information and knowledge related to products across their entire lifecycle. Extant product lifecycle management/product data management (PLM/PDM) software are limited when called to solve PLM challenges, like interoperability for instance. Industrial Internet platforms can provide real-time management of data and information along all the phases of a product's lifecycle. Platform openness, combined with industrial internet platform characteristics, helps to solve the PLM challenges. [62] raised several challenges and proposed a solution using industrial internet platform openness.

Another aspect to address through data management is traceability, intended as the ability to follow a product along its lifecycle [59]. It also guarantees product safety and quality throughout the supply chain, managing information generated by several players. Even though regulations establish the information that has to be traced, each player generates much more product (and process) information, which could be used to add value to products, with respect to, not only traceability, but also the lifecycle approach. [63] identified six industries (software, manufacturing, automotive, automation, aircraft, and aerospace) and seven subject areas (software engineering; system engineering; Industry 4.0; new product development; process management; data management; environmental 
sustainability) in which traceability and lifecycle approach are worthy to be directly connected through the use of several technologies (as sensing, IT platform, data storage and communication protocols). They claim the relevance of the possibility of tracking an item (product, requirements, data, food, and so on) to guarantee a high level of quality of the final product or service.

\section{DISCUSSION}

The literature analysed provides some hints to better define and characterize in the DIH concept each of the five dimensions detected.

A DIH being a business ecosystem, it is important to create a community composed of interrelated organizations. In particular, it is important to address the main objective of supporting SMEs digital transition involving in this process different stakeholders (technology providers and users, education and training hubs, market development experts, regional development associations, etc.). At the same time, DIHs need to support the digitalization of the solutions provided by manufacturers. Following the whole lifecycle of digital technologies from conception up to commercialisation [60], a dedicated support needs to be provided by DIHs to SMEs to develop and propose digitized, smart and connected products or solutions. Indeed, digital technologies are often added and embedded to traditional products to meet the changing customer needs, addressing phenomena as mass customization and servitization. However, to allow companies to deliver such new solutions, DIHs also need to help them reconfigure their business models, to more serviceand community-driven. In addition, manufacturing companies pursuing digitalization need to invest not only in technologies but also in human capital: new skills are needed, both hard and soft, to fully exploit the potentialities deriving from digital technologies adoption. DIHs are called to support companies in two ways to consolidate their inner capabilities. From one side, they could provide services to assess the status quo of the companies that want to approach digitization, in terms of both process/organization and skills maturity, and to set an adequate roadmap to empower it. The second is to support more directly companies' skill empowerment through educational programs or knowledgetransfer mechanisms (e.g., sharing channels). Finally, DIHs are called to provide services dealing with the different phases of the data lifecycle: from data acquisition and sensing, up to processing and sharing. However, several issues (as traceability, interoperability, integrability and openness) have been raised in this domain.

\section{CONCLUSION AND FUTURE DEVELOPMENTS}

This paper presented a literature review about the main dimensions that are needed to be considered by DIHs to support SMEs digital transition, i.e., ecosystem, technology, business, skills and data. Indeed, the main aim of the research has been to raise the awareness about each of these dimensions in the digital domain, providing theoretical evidence and raising the need of adding the skills and data dimensions of services to the traditional ecosystem, technology, and business ones. The resulting five dimensions have also been combined in the D-BEST model [61], for configuring the service portfolio of DIHs. However, this research is not free from limitations. The main one is that it has provided only a theoretical evidence of the need of the selected five D-BEST dimensions of services. This opens the way to plan several activities to raise their relevance also from a practical perspective. Indeed, based on these five dimensions, the reference model aimed to configure DIHs' service portfolio has been conceived, the D-BEST [61] will be validated in the network of the DIH4CPS project (that will be used as pilot case) and will be practically applied in different DIH networks operating in the European context. Finally, DIHs are always more offering Remotization Service to access and use their Data, Digital Twins, Software and physical Assets. This is even more needed due to COVID situation. Remotization services, enabling remote experimentation (through data space as a service, ICT as a service, simulation as a service, asset as a service), are thus envisaged as further macro-class to be analysed and added to the D-BEST model.

\section{ACKNOWLEDGMENT}

This work has received funding from the European Union's Horizon 2020 research and innovation programme under grant agreement No 872548.

\section{REFERENCES}

[1] M. Rüßmann et al., "Industry 4.0: The Future of Productivity and Growth in Manufacturing Industries,” 2015.

[2] C. Sassanelli, M. Rossi, and S. Terzi, "Evaluating the smart maturity of manufacturing companies along the product development process to set a PLM project roadmap," Int. J. Prod. Lifecycle Manag., vol. 12, no. 3, pp. 185-209, 2020.

[3] European Commission, "Digitising European Industry. Reaping the full benefits of a Digital Single Market," 2016.

[4] European Commission, "Digital Innovation Hubs in Smart Specialisation Strategies. Early lessons from European regions," 2018.

[5] M. Butter, G. Gijsbers, A. Goetheer, and K. Karanikolova, "Digital innovation hubs and their position in the European, national and regional innovation ecosystems," in Redesigning Organizations: Concepts for the Connected Society, Springer International Publishing, 2019, pp. 45-60.

[6] H. Markowitz, "Portfolio Selection," J. Finance, vol. 7, no. 1, pp. 77-91, Mar. 1952.

[7] R. Cooper, S. Edgett, and E. Kleinschmidt, "Portfolio management for new product development: Results of an industry practices study," R D Manag., vol. 31, no. 4, pp. 361-380, Oct. 2001.

[8] M. O’Loughlin, The Service Catalog: A Practitioner Guide, First. Amersfoort-NL, 2010.

[9] J. Banerjee and S. Aziz, "SOA: The missing link between Enterprise Architecture and Solution Architecture," in SETLabs Briefings, Enterprise Architecture (EA), Service Oriented Architecture (SOA), Solution Architecture (SOLA): The Missing Link?, 2007, p. Vol. 5. No. 2, pp. 69-80.

[10] A. Arsanjani, "Patterns: service-oriented architecture and web services," 2004.

[11] R. Sarno and A. Herdiyanti, "A Service Portfolio for an Enterprise Resource Planning," Int. J. Comput. Sci. Netw. Secur., vol. 10, no. 3 , p. 144,2010

[12] M. Janssen and R. Feenstra, "From application to service portfolio 
management: Concepts and practice," in Proceedings of the European Conference on e-Government, ECEG, 2006, pp. 225234.

[13] C. Rudd and V. Lloyd, ITIL Service Design. ITIL, 2007.

[14] T. Kohlborn, A. Korthaus, and M. Rosemann, "Business and Software Service Lifecycle Management A Theory of Innovation Systems View project Business Process Management in the Digital Age View project Business and Software Service Lifecycle Management," in EDOC 2009: 13th International Conference on Enterprise Computing, 2009.

[15] "The Multi Key Enabling Technologies Pilot lines project," 2020. [Online]. Available: http://www.mkpl.eu/home/. [Accessed: 26Oct-2020].

[16] SmartAgriHubs Project, "D4.2 DIH Capability Maturity Model_WP 4-DIH Capacity Building and Monitoring_Managing Maturity of the Digital Innovation Hub Innovation Services," 2020.

[17] "MIDIH Project," 2020. [Online]. Available: https://midih.eu/project.php. [Accessed: 26-Oct-2020].

[18] MIDIH Project, "D3.4 Specifications and Design of DIH/CC Services 2 - WP3 Network of Competence Centers and Pan-EU DIHs in CPS/IoT," 2020.

[19] A. G. Tansley, "The Use and Abuse of Vegetational Concepts and Terms," Ecology, vol. 16, no. 3, pp. 284-307, 1935.

[20] J. F. Moore, "Predators and Prey: A New Ecology of Competition," Harv. Bus. Rev., vol. May-June, pp. 75-86, 1993.

[21] P. MSEE, Manufacturing Service Ecosystem: Achievements of the European 7th Framework Programme FoF-ICT Project MSEE: Manufacturing SErvice Ecosystem (Grant No. 284860). 2014.

[22] Y. Ducq, D. Chen, and G. Doumeingts, "A contribution of system theory to sustainable enterprise interoperability science base," Comput. Ind., vol. 63, no. 8, pp. 844-857, Oct. 2012.

[23] H. A. Simon, The Sciences of the Artificial, Third Edit. 1969.

[24] M. D. Mesarovic, D. Macko, and T. Takahara, Theory of Hierarchical, Multilevel, Systems, Volume 68, First Edit. 1970.

[25] S. De Santis and M. Monetti, "Industry 4.0 for the future of manufacturing in the EU,” Roma, 2017.

[26] PwC and GMIS, "Industry 4.0: Building the Digital Industrial Enterprise," 2016.

[27] L. Monostori, "Cyber-physical production systems: Roots, expectations and R\&D challenges," Procedia CIRP, vol. 17, pp. 9-13, 2014.

[28] F. Piller and A. Kumar, "For each, their own: the strategic imperative of mass customization," Ind. Eng., vol. 38, no. 9, p. 40, 2006.

[29] F. Salvador, P. M. de Holan, and F. T. Piller, "Cracking the Code of Mass Customization,” MIT Sloan Manag. Rev., vol. 50, no. 3, pp. 71-78, 2009.

[30] P. Joseph, B. Victor, and A. C. Boynton, "Making Mass Customization Work," Harv. Bus. Rev., 1993.

[31] M. E. Porter and J. E. Heppelmann, "How Smart, Connected Products Are Transforming Companies," Harv. Bus. Rev., vol. 93, no. 10, pp. 96-114, 2015.

[32] M. E. Porter and J. E. Heppelmann, "How Smart, Connected Products Are Transforming Competition," Harv. Bus. Rev., no. November, pp. 64-89, 2014.
[33] W. Want, B. N. Schilit, and S. Jenson, "Enabling the Internet of things," Computer (Long. Beach. Calif)., vol. 48, no. 1, 2015.

[34] D. Ibarra, J. Ganzarain, and J. I. Igartua, "Business model innovation through Industry 4.0: A review," in Procedia Manufacturing, 2018, vol. 22, pp. 4-10.

[35] M. M. Iivari, P. Ahokangas, M. Komi, M. Tihinen, and K. Valtanen, "Toward ecosystemic business models in the context of industrial internet," J. Bus. Model., vol. 4, no. 2, pp. 42-59, Oct. 2016.

[36] Roundtable on Digitizing European Industry - WG1, "Digital Innovation Hubs: Mainstreaming Digital Innovation Across All Sectors Final version," 2017.

[37] K. Schwab, The Fourth Industrial Revolution. World Economic Forum, 2016.

[38] F. Acerbi, S. Assiani, and M. Taisch, "A research on hard and soft skills required to operate in a manufacturing company embracing the industry 4.0 paradigm," Proc. Summer Sch. Fr. Turco, vol. 1, pp. 1-12, 2019.

[39] B. Lamborghini, "Industry 4.0, le competenze sono il vero dilemma italiano," Agenda Digitale, 2017. .

[40] WMF Editorial Board, "2018 World Manufacturing Forum Report, Recommendations for the Future of Manufacturing," 2018.

[41] G. S. Becker, "Investment in Human Capital: A Theoretical Analysis," J. Polit. Econ., vol. 70, no. 5, Part 2, pp. 9-49, Oct. 1962.

[42] P. Romer, "Human Capital And Growth: Theory and Evidence," Cambridge, MA, Nov. 1989.

[43] T. W. Schultz, "The Economic Importance of Human Capital in Modernization,” Educ. Econ., vol. 1, no. 1, pp. 13-19, Jan. 1993.

[44] L. Gehrke et al., "Industry 4.0 A Discussion of Qualifications and Skills in the Factory of the Future: A German and American Perspective," 2015.

[45] P. J. Koch et al., "A Skill-based Robot Co-worker for Industrial Maintenance Tasks,” Procedia Manuf., vol. 11, pp. 83-90, 2017.

[46] A. A. Malik and A. Bilberg, "Framework to Implement Collaborative Robots In Manual Assembly: A Lean Automation Approach," 2017, pp. 1151-1160.

[47] L. Prifti, M. Knigge, H. Kienegger, and H. Krcmar, "A Competency Model for 'Industrie 4.0' Employees," in 13th International Conference on Wirtschaftsinformatik, 2017, pp. 4660.

[48] F. Hecklau, M. Galeitzke, S. Flachs, and H. Kohl, "Holistic Approach for Human Resource Management in Industry 4.0," Procedia CIRP, vol. 54, pp. 1-6, Jan. 2016.

[49] Hays, "China's tight talent market: The skills shortage may hinder growth warns Hays," 2016.

[50] The Manufacturer, “Annual Manufacturing Report,” 2018.

[51] A. Salerno, "Industria 4.0: Italia-Germania alleanza vincente?," corrierecomunicazioni.it, 2017.

[52] M. Lorenz, D. Küpper, M. Rüßmann, A. Heidemann, and A. Bause, "Time to Accelerate in the Race Toward Industry 4.0," 2016.

[53] WEF, "The Future of Jobs and Skills in the Middle East and North Africa," 2017.

[54] H. . Kagermann, W.-D. . Lukas, and W. Wahlster, "Industrie 4.0: 
Mit dem Internet der Dinge auf dem Weg zur 4. industriellen Revolution," VDI nachrichten, 13(11)., 2011.

[55] M. Piccarozzi, B. Aquilani, and C. Gatti, "Industry 4.0 in management studies: A systematic literature review," Sustain., vol. 10 , no. 10 , pp. 1-24, 2018.

[56] T. S. Ing, T. C. Lee, S. W. Chan, J. Alipal, and N. A. Hamid, “An overview of the rising challenges in implementing industry 4.0," Int. J. Supply Chain Manag., vol. 8, no. 6, pp. 1181-1188, 2019.

[57] H. Panetto, B. Iung, D. Ivanov, G. Weichhart, and X. Wang, "Challenges for the cyber-physical manufacturing enterprises of the future," Annual Reviews in Control, vol. 47. Elsevier Ltd, pp. 200-213, 01-Jan-2019.

[58] T. P. Raptis, A. Passarella, and M. Conti, "Data management in industry 4.0: State of the art and open challenges," IEEE Access, vol. 7, pp. 97052-97093, 2019.

[59] A. Corallo, M. E. Latino, M. Menegoli, and P. Pontrandolfo, “A systematic literature review to explore traceability and lifecycle relationship," International Journal of Production Research, vol. 58, no. 15. Taylor and Francis Ltd., pp. 4789-4807, 02-Aug-2020.

[60] K. T. Ulrich and S. D. Eppinger, Product Design and Development, vol. 384. 2012.

[61] C. Sassanelli, H. Panetto, W. Guedria, S. Terzi, and G. Doumeingts, "Towards a reference model for configuring services portfolio of Digital innovation hubs: the ETBSD model," in IFIP International Federation for Information Processing 2020, PROVE 2020, IFIP AICT 598, 2020, pp. 597-607. 